\title{
Logical Analysis of the Concept of Beauty
}

\author{
Fábio Maia Bertato*, Gabriel San Martin** \\ ( ${ }^{\star}$ University of Campinas (Unicamp), Centre for Logic, Epistemology, \\ and the History of Science, \\ ${ }^{* *}$ University of Campinas (Unicamp), Department of Philosophy)
}

\section{Introduction}

Besides his remarkable contributions to logic and its history, and as part of his intense philosophical activity, Józef Maria Bocheński carried out noteworthy investigations on concepts belonging to the most varied domains of knowledge. Among these, we highlight his input into discussions on the concepts of authority and free society. In these, Bocheński undertakes logical analyses in a methodology he developed himself, and that allows him to work with great conceptual precision and to obtain results relevant for understanding these crucial relationships in human societies.

Inspired by his methodology, we will carry out a logical analysis of the concept of beauty. We are not, however, aiming for the same level of depth achieved by Bocheński in his works. This is a first attempt at a logical treatment of an extremely slippery and controversial concept. Therefore, we do not wish to get involved in the philosophical dispute about what beauty means. Our approach is less pretentious than that, but we consider the results presented here to be relevant for those participating in discussions on philosophical aesthetics, consistently, from the perspective of classical logic. In fact, we analyze the truth values of some basic propositions about beauty based on certain assumptions on the 
domains of objects and subjects and two formal definitions concerning famous beliefs related to the concept of beauty. For this purpose, we use a kind of semantic neutrality that allows us to analyze other concepts whose extensions and definitions satisfy the same assumptions. We consider the most interesting result to be the one affirming that, even in a relativistic perspective, it is necessary to affirm the existence of an object that is either beautiful or non-beautiful and that is universally recognized as such by all subjects in the domain.

In section 1.1, we briefly discuss Bocheński's approach in his analyses of the concepts of authority and free society, which inspired our method. In section 2, we give a brief overview of how beauty was conceptualized in philosophy throughout history and of the classic discussions about it. In section 3, we undertake a logical analysis of the concept of beauty. In 3.1, we introduce two formal and very general definitions of beauty and give some examples of how they can formally capture the definitions and insights of some philosophical traditions. In 3.2, we discuss the conditions imposed on the domain of subjects. In 3.3, we present the assumptions on the extension of the concept of beauty as well as the recognition of beautiful and non-beautiful objects by the subjects. In 3.4, we give twelve basic propositions about beauty, based on the possible generalizations of beauty as a binary relation. In the same section, we assign truth values to these basic propositions. We discuss the possible valuations of open truth-value propositions according to the two definitions given in 3.1. Finally, we present some conclusions in section 4 .

\subsection{On Bocheński’s Analysis of the Concepts of Authority and Free Society}

Bocheński's philosophical activity could be succinctly described as philosophical analysis. ${ }^{1}$ In particular, his analytical papers can be considered a part of the Polish analytic philosophy programme, inaugurated by Kazimierz Twardowski and Jan Łukasiewicz. The latter's proposal of conceptual analysis strongly affected Bocheński’s approach. ${ }^{2}$

An interesting discussion of Bocheński's method of philosophical analysis can be found in M. Lechniak, Bocheński's Method of Philosophical Analysis and Contemporary Applied Ontology, "Studies in East European Thought" 2013, Vol. 65, pp. 17-26.

2 It is noteworthy that Bocheński is one of the founders of the Cracow Circle, which unfortunately was unable to implement its entire programme due to the dissolution of the group during World War II. As Jan Woleński remarks: "Let me note that Bocheński's works about the concepts of 
Bocheński's innovation in his analysis of the concept of authority can be summed up in two main points. First, he distinguishes between epistemic authority and deontic authority. Second, such a distinction makes it possible to explain the general form of authority through a triadic relation between a carrier, the subject, and a field. Thus, " $A(x, y, \alpha)$ " means that " $x$ (carrier) is an authority for $y$ (subject) in the field $\alpha$." Based on this formula, Bocheński introduces a series of interesting generalizations. ${ }^{3}$

Despite the interesting results obtained in his analysis of the concept of authority, it is his paper entitled The Concept of the Free Society that interests us most. ${ }^{4}$ In the paper, Bocheński presents a logical analysis of the concept of a free society, which presupposes the triadic relation of deontic authority. Thus, his investigation depends only on an intuitive interpretation of authority, which allows him to present, through generalizations of the formula " $F(x, j)$ " (for " $x$ is free in the domain $j$ "), ${ }^{5}$ twelve types of a priori societies with respect to freedom.

In this way, Bocheński proceeds to give successive definitions of a free society that culminates in what is, in our opinion, a successful definition, through the rigour of logical symbolism. His approach shows that it is possible to employ tools that are simple from a logical point of view, but that provide very precise and original results in philosophy.

We will proceed in a similar way to Bocheński, investigating beauty as a binary relation. ${ }^{6}$ However, we will evaluate the truth values of some basic propositions about beauty, which is possible thanks to certain assumptions about the domains of objects and subjects.

authority and the logic of religion are perhaps the extreme realization of the ideology of the Cracow Circle" - J. Woleński, Polish Attempts to Modernize Thomism by Logic (Bocheński and Salamucha), "Studies in East European Thought" 2003, Vol. 55, No. 4, p. 312, n. 21.

3 He discusses the concept of authority and its various types in the following works: J. Bocheński, On Authority, "Comunicaciones Libres" 1964, Vol. 5, pp. 45-46; J. Bocheński, The Logic of Religion, New York, NY 1965; J. Bocheński, An Analysis of Authority, in: Authority, ed. F. Adelmann, The Hague 1974, pp. 56-85; J.M. Bocheński, Was ist Autorität? Einführung in die Logik der Autorität, Freiburg 1974; J. Bocheński, On Authority, "South African Journal of Philosophy” 1989, Vol. 8, No. 2, pp. 61-65.

$4 \quad$ J. Bocheński, The Concept of the Free Society, “The Monist” 1986, Vol. 69, No. 2, pp. 207-215.

5 The formula $F(x, j)$ is defined by Bocheński as $\sim(\exists y) A(y, x, j)$, which means " $x$ is not subject to any deontic authority in $j$ " (cf. J. Bocheński, The Concept of the Free Society, op. cit., p. 207).

6 Ibid. Beauty can also be considered as a triadic relation, so that the object $(x)$ is beautiful to the subject $(\alpha)$ in context $(k)$. However, we will not discuss this further in this paper. 
To the best of our knowledge, Bocheński himself does not seem to have undertaken investigations in philosophical aesthetics, nor even carried out any analyses of the concept of beauty. Therefore, we believe that applying an approach inspired by Bocheński's methodology can be a relevant and original contribution to the logic of beauty and to formal aesthetics.

\section{On the Concept of Beauty}

Throughout most of the history of aesthetics, beauty has been its most emblematic topic. From Plato to Arthur Danto, beauty has been one of the main concepts in aesthetics and one of the most controversial themes in the history of Western philosophy. ${ }^{7}$ In modern aesthetics, though, the concept of beauty carries specific connotations and has taken on greater importance with the consolidation of the modern system of the arts since the early 1700 s. $^{8}$

The concept of beauty has engendered many philosophical problems, such as those related to the definition of beauty, the nature of beauty, to whether beauty is related to content instead of only formal elements, and to the superiority of one type of beauty over another. ${ }^{9}$ The topic of the nature of beauty has been debated by many well-known aesthetes. Philosophers understood beauty, among many other ways, as a type of pleasure, ${ }^{10}$ as a characteristic of objects based on a given

Hippias major 281a-304a; A. Danto, O abuso da beleza, São Paulo 2015.

8 See P. Kristeller, The Modern System of the Arts: A Study in the History of Aesthetics. Part I, "Journal of the History of Ideas" 1951, Vol. 12, No. 4, p. 499; P. Kristeller, The Modern System of the Arts: A Study in the History of Aesthetics. Part II, "Journal of the History of Ideas" 1952, Vol. 13, No. 1, p. 17.

9 We can see this, for example, in the different positions that characterized the traditional German idealist debate between Immanuel Kant and Georg Wilhelm Friedrich Hegel about the superiority of one type of beauty over another (for Kant, natural beauty over artistic beauty and, for Hegel, artistic beauty over natural beauty). See I. Kant, Critique of Judgement, trans. J.H. Bernard, New York, NY 1951; G.W.F. Hegel, Cursos de estética I, São Paulo 2001. For further reading, see G. Rebec, Natural vs. Artistic Beauty, "The Journal of Philosophy, Psychology and Scientific Methods” 1905, Vol. 2, No. 10, pp. 253-260.

10 G. Santayana, The Sense of Beauty, New York, NY 1955, pp. 11-13; Thomas Aquinas, ST I, q. 5, a. 4. "[B] eauty relates to the cognitive faculty; for beautiful things are those which please when seen" (ST I, q. 5, a. 4, ad 1). The concept of beauty as a type of pleasure in Aquinas (something that "pleases when seen") is reinforced and deeply discussed by Christopher Sevier in Aquinas on Beauty, Lanham 2015. 
ratio or on symmetry, ${ }^{11}$ or even as something related to morality, truth and happiness. ${ }^{12}$ But, along with the problems of the definition and nature of beauty, another key philosophical issue concerning beauty is its subjectivity/objectivity.

Since antiquity, philosophers have been discussing the subjectivity/objectivity of beauty. On the one hand, for some philosophers, such as Plato, beauty consists in an immanent property contained in the form of things, as he exposes in the Hippias major. In other words, for Plato beauty is a property, a characteristic, of objects: therefore, beauty should necessarily be objective. On the other hand, for philosophers such as David Hume, beauty is related to taste, as he states in his essay Of the Standard of Taste (1757). For Hume, beauty consists much more in a value linked to taste and subjectivity than in a property which is recognized by all subjects as beautiful, as thought by Plato. ${ }^{13}$

Thus, since beauty has been discussed by many thinkers throughout the history of ideas, can we determine whether it is an attribute, or whether it is relational? Is beauty an objective property of objects or a judgement/valuation about a personal representation of objects? If beauty is an attribute/property, then we can say that an object is beautiful if, and only if, beauty can be represented as a unary predicate. If beauty is relative to an individual (that is, it is a value or

11 F. Hutcheson, An Inquiry into the Original of Our Ideas of Beauty and Virtue, Indianapolis, IN 2004, p. 29; Vitruvius, On Architecture, trans. F. Granger, Cambridge 1970, pp. 26-27. For Hutcheson, an object is called beautiful when it "seems to be in a compound Ratio of Uniformity and Variety; so that where the Uniformity of Bodies is equal, the Beauty is as the Variety; and where the Variety is equal, the Beauty is as the Uniformity" - F. Hutcheson, An Inquiry into the Original of Our Ideas of Beauty and Virtue, op. cit., p. 29. For Vitruvius, the concept of beauty is directly linked to the concept of venustas - which, on a basic level, refers to concepts such as those of symmetry and harmony.

12 J. Armstrong, The Secret Power of Beauty, London 2004. For John Armstrong, beauty is found in acquiring "spiritual value (truth, happiness, moral ideals) at home in a material setting (rhythm, line, shape, structure) and in a way that, while we contemplate the object, the two seem inseparable" (ibid., p. 163).

13 Some philosophers, such as Immanuel Kant and Roger Scruton, also opposed the absolute subjectivity of beauty as a value, judgement or feeling, affirming, in this way, that beauty consists in a judgement which is rationally founded and has a degree of objectivity (objectivity that makes it capable of being at least communicable). See I. Kant, Crítica da faculdade de julgar, trans. F. Costa Mattos, Petrópolis 2016, pp. 132-136; I. Kant, Observations on the Feeling of the Beautiful and Sublime, in: Observations on the Feeling of the Beautiful and Sublime and Other Writings, eds. P. Frierson, P. Guyer, New York, NY 2011, pp. 13-18; R. Scruton, Beauty, New York, NY 2009, pp. 195-197. 
a judgement), then we can state that an object is beautiful if, and only if, beauty can be represented as a binary relation.

Perhaps there is a little less disagreement about the meaning of a free society in the civilized world (at least in terms of the universal and theoretical acceptance of human rights) than in the field of philosophical aesthetics, which has been a challenge since its beginning. However, in this paper, instead of trying to present a precise definition of beauty, we will focus on the analysis of the truth values of some basic propositions about beauty, so that they can be interpreted according to different positions on the matter. And, surprisingly, such an analysis leads to interesting conclusions concerning propositions about the existence of universally recognized objects, either beautiful or non-beautiful.

It is possible that there are other aesthetic values besides beauty and ugliness, and so we will not assume that non-beautiful is a synonym for ugly. According to some authors, such as Danto, there are objects that, in certain contexts, for example, have no aesthetic value, being neutral or just useful. ${ }^{14}$

\section{Logical Analysis of the Concept of Beauty}

In this section, we introduce two formal definitions of beauty, from the perspective of recurring patterns found in various philosophical definitions in which these concepts come to be expressed with reasonable clarity. Below, we present the fundamental background which, according to us, is needed to perform a logical analysis of the concept of beauty. For this purpose, we establish the conditions that must be satisfied by the domain of subjects, and we identify assumptions that will allow us to evaluate the truth values of basic propositions about beauty.

\subsection{Two Formal Definitions of Beauty}

Regardless of how beauty is defined or how the meaning of the expression " $x$ is beautiful" is established, we can identify the following patterns.

14 The Dadaist artist Marcel Duchamp, for example, once said that his readymades had the fundamental objective of having "no beauty, no ugliness, nothing particularly aesthetic" about them; they were supposed to be "as nonsensical as possible." The topic of Duchamp's nonsensical/nonaesthetic objects has been addressed by authors such as Arthur Danto or Calvin Tomkins. See A. Danto, O abuso da beleza, op. cit., pp. 108-109; C. Tomkins, The World of Marcel Duchamp, New Jersey, NJ 1972, pp. 38-39. 
In a universalistic sense, one could consider that

(i) to say that $x$ is beautiful means to say that $x$ is beautiful for everyone.

In turn, in relativistic perspective, we would claim that

(ii) to say that $x$ is beautiful means to say that $x$ is beautiful for someone.

In such cases, we can distinguish the use of "beautiful" as a unary predicate (i) and as a binary relation (ii). Substituting " $B(x)$ " for " $x$ is beautiful" and " $\beta(x, \alpha)$ " for " $x$ is beautiful for the subject $\alpha$," we can rewrite (i) and (ii) as follows:

(i) $B(x) \equiv \forall \alpha \beta(x, \alpha)$;

(ii) $B(x) \equiv \exists \alpha \beta(x, \alpha)$.

We will call formulas (i) and (ii) the universalistic and relativistic definitions of beauty, respectively. We must stress that in this case the meaning of the terms universalistic and relativistic is determined by the use of universal and existential quantifiers in the formulas. Interpretations of such formulas may contemplate several underlying philosophies of beauty. For the logical analysis carried out here, we do not need to adopt any specific philosophical position regarding beauty. Thus, if a certain philosophical conception is such that it admits the efficacy of classical logic and assigns the truth value true to our assumptions, then the conclusions presented here must be consequences in its philosophical system.

The universalistic and relativistic definitions establish two connections between the predicate "beautiful" and the binary relation "beautiful for a subject." What the latter means formally or informally depends on the theory of beauty underlying the adopted semantics. For example, Marcia Eaton claims that cognitive theories of beauty take the following form:

(CT) $x$ is beautiful if, and only if, attention to intrinsic properties of $x$ yields pleasurable perceptual experiences in an informed observer who is observing $x .^{15}$

There are two possibilities of interpretation here. If the domain of subjects consists only of informed observers, then (CT) can be interpreted as a universalistic definition and "beautiful" in " $x$ is beautiful" is a predicate. If the domain

15 M. Eaton, Beauty and Ugliness In and Out of Context, in: Contemporary Debates in Aesthetics and Philosophy of Art, ed. M. Kieran, Oxford 2006, p. 46. 
of subjects includes non-informed observers, then (CT) can be interpreted from a relativistic perspective, so that " $x$ is beautiful" means tacitly " $x$ is beautiful to an observer/subject."

In both cases, we could claim that the second member (the definiens) of the equivalence in (CT) establishes the binary relation in question. Thus, one possibility of symbolizing (CT) is

$$
\text { (CT) } B(x) \equiv \forall \alpha(O I(\alpha, x) \& P P(x, \alpha)) \text {, }
$$

where "OI $(\alpha, x)$ " stands for " $\alpha$ is an informed observer who is observing $x$ "; " $P P(x, \alpha)$ " stands for "attention to intrinsic properties of $x$ yields pleasurable perceptual experiences in $\alpha$ "; and " $\beta(x, \alpha)$ " is equivalent to " $O I(\alpha, x) \& P P(x, \alpha)$." This last equivalence would allow us to consider (CT) a definition of the universalistic type (i).

In any case, the values of formulas (i) and (ii) depend on the domains of objects and subjects.

With that in mind, some examples of universalists could be:

(a) objectivists, who claim that beauty is objective and that a beautiful object is recognized as such by all subjects.

(b) conventionalists, who think that beauty is a convention, recognized by everyone involved in it. In this case, the domain of subjects must be restricted.

(c) cognitivists, who believe that a beautiful object can be recognized by every subject with the necessary knowledge. In this case, the domain of subjects must also be restricted.

On the other hand, some examples of relativists could be:

$\left(a^{\prime}\right)$ subjectivists, who argue that the foundation of an object's aesthetic value lies in the subject. In this case, it only makes sense to say that something is beautiful for the subject himself. ${ }^{16}$

16 The most-known defenders of this position are Hume and Kant; see D. Hume, Of the Standard of Taste, in: Essays Moral, Political, and Literary, ed. E.F. Miller, Indianapolis, IN 1987; I. Kant, Critique of Judgement, op. cit.; I. Kant, Observations on the Feeling of the Beautiful and Sublime, op. cit.; I. Kant, Crítica da faculdade de julgar, op. cit. Hume, for example, once affirmed that "beauty is no quality in things themselves: It exists merely in the mind which contemplates them; and each mind perceives a different beauty" - D. Hume, Of the Standard of Taste, op. cit., p. 139. It is important to note that, even being subjectivists, neither Kant nor Hume have defended that beauty is not at least a communicable value - which expresses, to some extent, a minimal degree of objectivity in their conception of the subjectivity of beauty. 
$\left(b^{\prime}\right)$ aesthetic relativists, who assume that aesthetic value depends solely on an individual or on the social group. In this case, the domain of subjects is partitioned, and something is beautiful only as a reference to a subset of such a domain.

$\left(c^{\prime}\right)$ strong cognitivists, who argue that no landscape untouched by humans can be non-beautiful. In this case, it is sufficient that there is at least one subject informed well enough to perceive the beauty of natural objects. ${ }^{17}$

Since there are some inaccuracies in the attempts to define beauty in different schools of thought, the examples above depend on a certain interpretation and manipulation of the domains of objects and subjects. Thus, for example, a cognitivist who is more like a relativist can also be considered a universalist in a restricted domain. In other words, categories (b), (c), ( $\left.b^{\prime}\right)$, and $\left(c^{\prime}\right)$ have a certain degree of neutrality with respect to the formal definitions presented above, even though they tend to belong to one side (as a universalist or a subjectivist). The only categories listed here which are necessarily characterized as universalists or relativists in a strong sense are, respectively, (a) and ( $\left.a^{\prime}\right)$. That is, it is impossible for an individual to be simultaneously an objectivist and a subjectivist. Otherwise, an individual can simultaneously be a cognitivist and a relativist or a strong cognitivist and a universalist. This is because, in these two last cases, the properties of being a cognitivist or a stronger cognitivist are not necessarily linked to the property of being a universalist or a relativist, respectively.

In the following, we discuss the domain of subjects who can enter into relations with objects, which can be judged as beautiful or non-beautiful.

\subsection{The Domain of Subjects}

As a criterion for establishing the domain of subjects, we will consider it to be a set of skilled agents. In what follows, we will clarify what it means to say skilled agents.

It is expected that for a subject to be able to make aesthetic judgements about objects, he or she must be able to access it in some way. Let us assume that each

17 This specific category of cognitivists (which, here, we named strong cognitivists) is presented by Eaton in Beauty and Ugliness In and Out of Context, op. cit., pp. 47-48. An example of an author that defended this position is Allen Carlson - see his Nature and Positive Aesthetics, "Environmental Ethics" 1984, Vol. 6, No. 5, p. 5. 
object has certain properties that require specific skills/abilities to be accessed. It follows, then, that we will assume that the subjects have such skills/abilities.

As is well known, discussions on beauty end up orbiting around two classic possibilities: beauty is in the object, or beauty is in the eye of the beholder. ${ }^{18}$ If beauty is objective, then we can say that the object is beautiful due to its intrinsic properties. If beauty is subjective, then the object is subjectively beautiful, that is, it is beautiful to someone. On one hand, if we admit that beauty is objective, the beautiful object can only be perceived as beautiful by someone who can access its intrinsic properties. On the other hand, if we admit that it is subjective, then for an object to be considered subjectively beautiful by a subject, it is necessary that the object can be accessed in some way, which corresponds to access to some properties of that object.

Let us take the example of visual objects. In order to be considered visually beautiful, it is necessary to be visually perceived. It can be said that people incapable of visual perception do not have the minimum skill/ability necessary to consider something visually beautiful, whether beauty is objective or subjective.

In addition, to be a skilled agent a subject depends on certain psychological, cognitive, and epistemic states. For our goal, we stipulate that the subjects have a minimally stable cognition, that is, that they are individual persons without very serious mental or psychological disorders. Thus, people who have conditions so extreme as to prevent them from considering anything beautiful are not in the domain of subjects.

Once the conditions for the domain of subjects are stated, we can establish some assumptions that will guide our analysis.

\subsection{The Assumptions}

From a very general point of view on the concept of beauty, we will adopt the following propositions as assumptions.

A1. Not everything falls within the scope of the concept of beauty;

A2. Something falls within the scope of the concept of beauty;

18 These expressions are related, respectively, to the possibilities of objectivity and subjectivity in beauty. The phrase "beauty is in the eye of the beholder," referring to the subjectivity of beauty, was first used by Margaret Hungerford, in her novel Molly Bawn (1878). 
A3. Every subject recognizes at least one object as beautiful and at least one object as non-beautiful.

Assumption A1 guarantees that the extension of the concept is not the totality of things. Assumption A2, in turn, expresses the fact that the extension is not empty. Both avoid the trivialization (totality or emptiness) of the concept of beauty. The third assumption guarantees the same for beauty as a binary relation. Such assumptions avoid two extreme cases, namely, saying that everything is beautiful or saying that nothing is beautiful.

Extreme cases can occur in certain artificial situations in which the concept of beauty would not be treated in its true scope. For example, suppose that the domain of objects is a collection formed by the Parthenon, the Niagara Falls, and Duchamp's Fountain. Furthermore, let the domain of subjects be determined by, say, four individuals who consider the three "objects" to be beautiful. In this case, we would have that the extension of the local concept of beauty would be the whole domain, both in the relativistic and in the universalistic sense. Now, if the domain is a set of people who do not consider any of the three objects beautiful, then the extension of the local concept would be empty. Notwithstanding these possibilities, it does not seem to be the state of affairs in reality, when we consider the domains formed by all things and all subjects (possibly within a certain period of time). ${ }^{19}$

Rewriting the assumptions with symbols, we obtain the following formulas:

A1. $\neg \forall x B(x)$ (which is equivalent to either $\neg \forall x \forall \alpha \beta(x, \alpha)$ or $\neg \forall x \exists \alpha \beta(x, \alpha)$ );

A2. $\exists x B(x)$ (which is equivalent to either $\exists x \forall \alpha \beta(x, \alpha)$ or $\exists x \exists \alpha \beta(x, \alpha)$ );

A3. $\forall \alpha \exists x \exists y(\beta(x, \alpha) \& \neg \beta(y, \alpha))$.

Based on these assumptions, we can evaluate the truth values of basic propositions about beauty.

19 In order to avoid problems such as those generated by Russell's Paradox, we could consider the domain of objects to be the set of all real or actual objects, assuming that a set is not a real being. In this way, it seems reasonable to speak of the totality of (actual) things. 


\subsection{Twelve Basic Propositions on Beauty as a Binary Relation}

Using the formula $\beta(x, \alpha)$ it is possible to establish twelve different basic formulas on beauty. Since we have made assumptions about the domains of objects and subjects, we can determine the truth value of most of these propositions. In fact, only in the case of two pairs of contradictory formulas are the truth values a priori open. Thus, given the context of a reflection in aesthetics, we can identify the advantages and disadvantages of assuming certain statements to be true. Next, we present the twelve possibilities of generalization of quantifiers on the binary relation.

We proceed now to list the different basic propositions on beauty. There are, first, two generalizations of one of the variables, either " $x$ " or " $\alpha$ ". Thus, we need to determine the number of formulas obtained from the combination quantifiervariable-quantifier-variable- $\beta(x, \alpha)$. This is a very simple problem in combinatorics; the solution is $2 \times 2 \times 2 \times 1=8$ formulas. Similarly, we will have eight quantified formulas on $\neg \beta(x, \alpha)$, which results in a total of sixteen generalizations. However, the order of variables for two equal quantifiers is irrelevant. Thus, there are twelve different possible generalizations. Table 1 presents these twelve possibilities, where we omit $\beta(x, \alpha)$ for brevity.

Table 1

\begin{tabular}{ll}
\hline 1. $\forall x \forall \alpha$ and $\forall \alpha \forall x$ & 7. $\exists x \exists \alpha \neg$ and $\exists \alpha \exists x \neg$ \\
2. $\exists \alpha \forall x$ & 8. $\forall \alpha \exists x \neg$ \\
3. $\forall x \exists \alpha$ & 9. $\exists x \forall \alpha \neg$ \\
4. $\exists x \forall \alpha$ & 10. $\forall x \exists \alpha \neg$ \\
5. $\forall \alpha \exists x$ & 11. $\exists \alpha \forall x \neg$ \\
6. $\exists x \exists \alpha$ and $\exists \alpha \exists x$ & $12 . \forall x \forall \alpha \neg$ and $\forall \alpha \forall x \neg$ \\
\hline
\end{tabular}

The "dodecagon" (Figure 1) below presents all twelve formulas, and it indicates some implications through arrows (for example, formula 1 implies 2, 3, 4, etc; formula 2 implies 3 ; and so on). Contradictory formulas can be identified by their diametrically opposite position according to the analogue clock. Thus, formulas 1 and 7 are contradictory; 2 and 8 are contradictory; 3 and 9 are contradictory; and so on. 


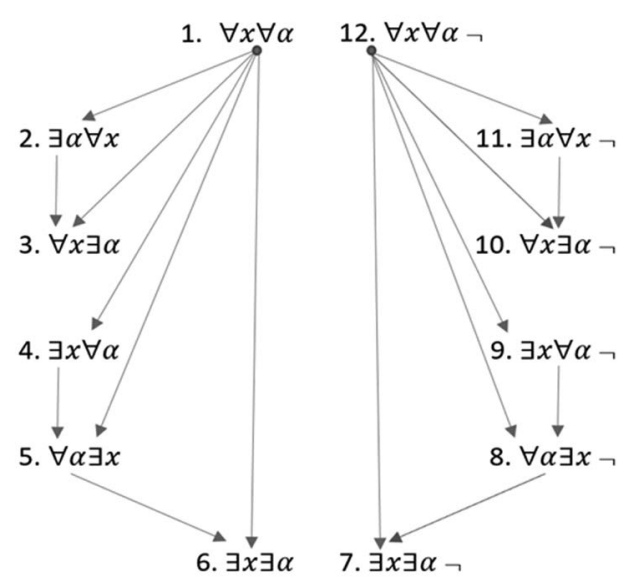

Figure 1

In the following, we present natural-language interpretations of the twelve basic formulas and we also evaluate each one.

1. $\forall x \forall \alpha \beta(x, \alpha)$

All objects are beautiful for all subjects.

This means that everything is beautiful for everyone. If this formula is true, then the extension is the universe, but this contradicts assumption A1. Moreover, it contradicts assumption A3 as well. Therefore, formula 1 is false.

\section{2. $\exists \alpha \forall x \beta(x, \alpha)$}

There is at least one subject for whom all objects are beautiful.

Formula 2 says that someone recognizes beauty in everything. But it contradicts assumption A3. Therefore, formula 2 is false.

\section{3. $\forall x \exists \alpha \beta(x, \alpha)$}

For every object, there is at least one subject who recognizes its beauty.

According to the universalistic definition of beauty, formula 3 can be true or false. In the relativistic sense, it is false, because it contradicts assumption A1. 
4. $\exists x \forall \alpha \beta(x, \alpha)$

There is at least one object that is beautiful for all subjects.

Formula 4 means that there exists at least one case of universal beauty, that is, something that is beautiful for everyone, an object that is universally recognized as beautiful. In the universalistic sense, it is true. It can be true or false according to the relativistic definition of beauty.

5. $\forall \alpha \exists x \beta(x, \alpha)$

For all subjects, there is at least one object that is beautiful.

This formula affirms that everyone recognizes that something is beautiful. According to assumption A3, formula 5 is true. Otherwise, we would have to assume that someone from the domain of subjects thinks that everything is nonbeautiful.

6. $\exists x \exists \alpha \beta(x, \alpha)$

There is at least one object that is beautiful for at least one subject.

This means that something is beautiful for someone. We could say that this fact is empirically verifiable, since it is easy to find someone who considers at least one object to be beautiful. In any case, formula 6 follows from formula 5 . Therefore, it is true.

\section{7. $\exists x \exists \alpha \neg \beta(x, \alpha)$}

There is at least one object that is not beautiful for at least one subject.

Such a formula says that something is non-beautiful for someone. It follows from assumption A3. Furthermore, it is contradictory to formula 1, which is false. Thus, formula 7 is true.

8. $\forall \alpha \exists x \neg \beta(x, \alpha)$

For all subjects, there is at least one object that is not beautiful.

It also follows from assumption A3. In addition, it is contradictory to formula 2, which is false. Therefore, formula 8 is true.

9. $\exists x \forall \alpha \neg \beta(x, \alpha)$

There is at least one object that is not beautiful for all subjects. 
Analogously to formula 4, this formula means that there exists at least one case of universal non-beauty, that is, something that is non-beautiful for everyone. In the universalistic sense, it can be true or false. It is true according to the relativistic definition, because if its contradictory were true (formula 3 ), then the concept of beauty would be trivialized (everything would be beautiful).

10. $\forall x \exists \alpha \neg \beta(x, \alpha)$

For every object, there is at least one subject who does not recognize its beauty.

This formula is false in the universalistic sense, since it is the contradictory of formula 4 (otherwise the extension of the concept would be empty). Just like formula 4 , it can be true or false according to the relativistic definition of beauty.

11. $\exists \alpha \forall x \neg \beta(x, \alpha)$

There is at least one subject for whom all objects are not beautiful.

It contradicts assumption A3. Furthermore, it is the contradictory of formula 5 , which is true. It follows that its truth value is false.

12. $\forall x \forall \alpha \neg \beta(x, \alpha)$

All objects are not beautiful for all subjects.

This formula means that nothing is beautiful. It contradicts assumption A2 and formula 6 , which is true. Therefore, formula 12 is false.

The following table summarizes the valuations established so far.

Table 2

\begin{tabular}{llrl}
\hline $1 . \forall x \forall \alpha$ & $\mathrm{F}$ & $7 . \exists x \exists \alpha \neg$ & $\mathrm{T}$ \\
2. $\exists \alpha \forall x$ & $\mathrm{~F}$ & $8 . \forall \alpha \exists x \neg$ & $\mathrm{T}$ \\
3. $\forall x \exists \alpha$ & $?$ & $9 . \exists x \forall \alpha \neg$ & $?$ \\
$4 . \exists x \forall \alpha$ & $?$ & $10 . \forall x \exists \alpha \neg$ & $?$ \\
$5 . \forall \alpha \exists x$ & $\mathrm{~T}$ & $11 . \exists \alpha \forall x \neg$ & $\mathrm{F}$ \\
$6 . \exists x \exists \alpha$ & $\mathrm{T}$ & $12 . \forall x \forall \alpha \neg$ & $\mathrm{F}$ \\
\hline
\end{tabular}


We now know which basic propositions about beauty are true, regardless of which of the two formal definitions of beauty is adopted. Next, we will evaluate the two pairs of propositions with open truth-values, considering each definition.

\subsection{Evaluating the Open Truth-Value Propositions According to the Two Formal Definitions of Beauty}

In this section, we present four possible formal theories about beauty, based on the valuation of formulas with open truth-values.

\subsubsection{The Universalistic Context}

First, let us suppose that the universalistic definition of beauty applies. Then,

(i) $\quad B(x) \equiv \forall \alpha \beta(x, \alpha)$

is the formal definition of beauty to be considered.

From the valuations made in section 3.4, we have that formula 4, that is, $\exists x \forall \alpha \beta(x, \alpha)$, is true. This means that there is at least one object that is beautiful for all subjects, which we call a universal beauty. This was already expected, because, in the universalistic context, every object to which the predicate beautiful is applied is a universal beauty, since to be beautiful means to be beautiful for everyone. Thus, Table 3 indicates the truth values of the basic formulas in this context.

Table 3

\begin{tabular}{llrl}
\hline 1. $\forall x \forall \alpha$ & F & 7. $\exists x \exists \alpha \neg$ & T \\
2. $\exists \alpha \forall x$ & F & 8. $\forall \alpha \exists x \neg$ & T \\
3. $\forall x \exists \alpha$ & ? & 9. $\exists x \forall \alpha \neg$ & ? \\
4. $\exists x \forall \alpha$ & T & $10 . \forall x \exists \alpha \neg$ & F \\
5. $\forall \alpha \exists x$ & T & $11 . \exists \alpha \forall x \neg$ & F \\
6. $\exists x \exists \alpha$ & T & $12 . \forall x \forall \alpha \neg$ & F \\
\hline
\end{tabular}

One of the two contradictory formulas ( 3 and 9) must be true. Next, let us analyze each case.

1. $\forall x \exists \alpha \beta(x, \alpha)$ is true. 
If formula 3 is true, then we a have a universalistic-relativistic theory of beauty. It is universalistic in the sense that it assumes that every beautiful object is universally recognized as such. It is also relativistic because each object is beautiful for at least one of the subjects, that is, every object is relatively beautiful.

2. $\exists x \forall \alpha \neg \beta(x, \alpha)$ is true.

If formula 9 is true, then we a have a universalistic theory of beauty and nonbeauty. In this case, in addition to a universal beauty, we also have a universal non-beauty, that is, an object universally recognized as non-beautiful.

\subsubsection{The Relativistic Context}

Now, let us consider the relativistic definition of beauty. In this case,

(ii) $\quad B(x) \equiv \exists \alpha \beta(x, \alpha)$

is the corresponding formal definition of beauty.

Again, from the valuations made in 3.4, we have that formula 9, that is, $\exists x \forall \alpha \neg \beta(x, \alpha)$, is true. At this point we arrive at an unexpected consequence, namely, the affirmation of the existence of something universally recognized by the subjects as non-beautiful. Apparently, in a relativistic context, universal statements of this kind should be avoided, that is, it does not seem very relativistic to assume propositions stating that a certain judgement is made by all subjects in the domain. This fact is surprising, especially if we consider the domain of subjects to be all living people today or even all human beings. The alternative would be to conclude that formula 3 is true, but, in this case, the concept would be trivialized, and so everything would be beautiful. Table 4 indicates the truth values of the basic formulas in this relativistic context.

Table 4

\begin{tabular}{llrl}
\hline 1. $\forall x \forall \alpha$ & $\mathrm{F}$ & $7 . \exists x \exists \alpha \neg$ & $\mathrm{T}$ \\
2. $\exists \alpha \forall x$ & $\mathrm{~F}$ & $8 . \forall \alpha \exists x \neg$ & $\mathrm{T}$ \\
3. $\forall x \exists \alpha$ & $\mathrm{F}$ & $9 . \exists x \forall \alpha \neg$ & $\mathrm{T}$ \\
4. $\exists x \forall \alpha$ & $?$ & $10 . \forall x \exists \alpha \neg$ & $?$ \\
5. $\forall \alpha \exists x$ & $\mathrm{~T}$ & $11 . \exists \alpha \forall x \neg$ & $\mathrm{F}$ \\
$6 . \exists x \exists \alpha$ & $\mathrm{T}$ & $12 . \forall x \forall \alpha \neg$ & $\mathrm{F}$ \\
\hline
\end{tabular}


1. $\exists x \forall \alpha \beta(x, \alpha)$ is true.

If formula 4 is true, then we have here a relativistic-universalistic theory of beauty. It is relativistic since it assumes that for an object to be beautiful it is enough that at least one subject considers it so. It is universalistic because in this context there is a universal beauty.

2. $\forall x \exists \alpha \neg \beta(x, \alpha)$ is true.

If that is the case, then what we have here is a set of propositions that configure something that we could call the theory of universal non-beauty. It is so because, on the one hand, there would be an object universally recognized as non-beautiful, and, on the other hand, each object would be considered non-beautiful for at least one subject.

\section{Conclusions}

In short, using an approach inspired by Bocheński, we were able to carry out a logical analysis of the concept of beauty, in order to investigate the truth values of certain basic propositions regarding beauty. For this purpose, we considered two formal definitions of beauty that establish two connections between beauty as a predicate and beauty as a binary relation. In each case, that is, in the universalistic and relativistic contexts, there remains a set of contradictory propositions with undetermined truth values. Thus, we conclude that one can assume a priori four types of theories of beauty, namely, the universalistic-relativistic theory of beauty, the universalistic theory of beauty and non-beauty, the relativistic-universalistic theory of beauty, and the theory of universal non-beauty. In the universalistic context, it is not surprising that we must conclude that a universal beauty exists, since this follows from the very definition of beauty and the nonemptiness of the domain of objects. In the case of the relativistic context, however, the conclusion that we should assume the existence of a universal non-beauty does not seem obvious. Furthermore, we believe that for the purpose of a relativistic investigation in philosophical aesthetics, it is more appropriate to adopt the relativistic-universalistic theory of beauty. This is because in the relativistic context there remains the choice between the assumption of a universal beauty and the conclusion that everything is relatively non-beautiful. If the latter is the case, 
then the true basic propositions are essentially immediate consequences of the assumptions made here, plus two universal propositions about the non-beautiful. Furthermore, if non-beauty is a synonym of ugliness, then that would mean there is something that is considered ugly for everyone and everything is relatively ugly. And that would be more like a theory of ugliness than a theory of beauty.

Therefore, the relativistic-universalistic theory of beauty is the most interesting in the relativistic context. However, it is nonetheless surprising that the assumption about the existence of a universal beauty is preferable. One is not expected, in a relativistic context, to assume universal propositions of this nature, except for the proposition asserting that everything is relative.

Furthermore, we note that it is possible to build a formal first-order theory corresponding to each of the four theories discussed. In this case, formulas 5,6 , 7 , and 8 would be theorems common to the four theories, assuming only one of the formal definitions of beauty and the formal versions of the assumptions as axioms. Finally, it is worth mentioning that the approach proposed here can be used to analyze other concepts.

\section{Bibliography}

Armstrong J., The Secret Power of Beauty, London 2004.

Bocheński J., An Analysis of Authority, in: Authority, ed. F. Adelmann, The Hague 1974, pp. 56-85.

Bocheński J., The Concept of the Free Society, “The Monist” 1986, Vol. 69, No. 2, pp. 207-215, https://doi.org/10.5840/monist198669212.

Bocheński J., The Logic of Religion, New York, NY 1965.

Bocheński J., On Authority, “Comunicaciones Libres” 1964, Vol. 5, pp. 45-46, https://doi.org/10.5840/wcp131964V5.

Bocheński J., On Authority, "South African Journal of Philosophy" 1989, Vol. 8, No. 2, pp. 61-65.

Bocheński J.M., Was ist Autorität? Einführung in die Logik der Autorität, Freiburg 1974.

Brożek A., Bocheński on Authority, "Studies in East European Thought" 2013, Vol. 65, No. 1-2, pp. 115-133, https://doi.org/10.1007/s11212-013-9175-9. 
Carlson A., Nature and Positive Aesthetics, "Environmental Ethics" 1984, Vol. 6, No. 5, pp. 5-34, https://doi.org/10.5840/enviroethics19846114.

Danto A., The Abuse of Beauty, Chicago 2003.

Danto A., O abuso da beleza, São Paulo 2015.

De Clercq R., Beauty, in: Routledge Companion to Aesthetics, 3rd ed., eds. B. Gaut, D. Lopes, London 2013.

Eaton M., Beauty and Ugliness In and Out of Context, in: Contemporary Debates in Aesthetics and Philosophy of Art, ed. M. Kieran, Oxford 2006, pp. 39-50.

Eco U., On Beauty, trans. A. McEwen, London 2004.

Ginsborg H., The Normativity of Nature: Essays on Kant's Critique of Judgement, Oxford 2014.

Hegel G., Cursos de estética I, São Paulo 2001.

Hume D., Of the Standard of Taste, in: Essays Moral and Political, London 1894.

Hume D., Of the Standard of Taste, in: Essays Moral, Political, and Literary, ed. E.F. Miller, Indianapolis, IN 1987, pp. 137-149.

Hungerford M., Moly Bawn, Scotts Valley 2016.

Hutcheson F., An Inquiry into the Original of Our Ideas of Beauty and Virtue, Indianapolis, IN 2004.

Kant I., Crítica da faculdade de julgar, trans. F. Costa Mattos, Petrópolis 2016.

Kant I., Critique of Judgement, trans. J.H. Bernard, New York, NY 1951.

Kant I., Observations on the Feeling of the Beautiful and Sublime, in: Observations on the Feeling of the Beautiful and Sublime and Other Writings, eds. P. Frierson, P. Guyer, New York, NY 2011.

Kirwan J., Beauty, Manchester 1999.

Kristeller P., The Modern System of the Arts: A Study in the History of Aesthetics. Part I, "Journal of the History of Ideas" 1951, Vol. 12, No. 4, pp. 496-527, https://doi.org/10.2307/2707484.

Kristeller P., The Modern System of the Arts: A Study in the History of Aesthetics. Part II, "Journal of the History of Ideas" 1952, Vol. 13, No. 1, pp. 17-46, https:// doi.org/10.2307/2707724.

Lechniak M., J.M. Bocheński's Method of Philosophical Analysis and Contemporary Applied Ontology, "Studies in East European Thought" 2013, Vol. 65, pp. 17-26, https://doi.org/10.1007/s11212-013-9180-z.

Mothersill M., Beauty Restored, Oxford 1984. 
Mothersill M., Beauty, in: A Companion to Aesthetics, 2nd ed., eds. S. Davies et al., Oxford 2009.

Plato, Hippias major, trans. L. Angioni, "Archai" 2019, Vol. 26, e02608, https:// doi.org/10.14195/1984-249X_26_8.

Rebec G., Natural vs. Artistic Beauty, "The Journal of Philosophy, Psychology and Scientific Methods" 1905, Vol. 2, No. 10, pp. 253-260, https://doi.org/10.2307/ 2010869.

Richer P., Perspectives in Aesthetics: Plato to Camus, New York, NY 1967.

Santayana G., The Sense of Beauty, New York, NY 1955.

Scruton R., Beauty, New York, NY 2009, https:/doi.org/10.1093/actrade/ 9780199229758.001.0001.

Sevier C., Aquinas on Beauty, Lanham 2015.

Thomas Aquinas, The Summa theologica, 2nd rev. ed., trans. Fathers of the English Dominican Province, London 1920.

Tomkins C., The World of Marcel Duchamp, New Jersey, NJ 1972.

Vitruvius, On Architecture, trans. F. Granger, Cambridge 1970.

Woleński J., Polish Attempts to Modernize Thomism by Logic (Bocheński and Salamucha), "Studies in East European Thought" 2003, Vol. 55, No. 4, pp. 299-313.

\section{Summary}

Since antiquity, defining the concept of beauty has been a struggle for philosophers. Many raised questions related to the objectivity/subjectivity of beauty, which then became fundamental to the understanding of issues in philosophical aesthetics. In this context, our paper provides a logical analysis of the concept of beauty, which includes both universalistic and relativistic perspectives. Based on a methodology inspired by Józef Maria Bocheński's logical analyses of the concepts of authority and free society, we intend to present some unexpected results derived from popular beliefs and to propose solutions concerning this issue.

Key words: beauty, logic, aesthetics, formal approaches 